\title{
FORMALIZED QUALITATIVE MODELING OF ONLINE TRUST: INTRODUCTION OF THE METHOD AND A DETAILED EXAMPLE
}

\author{
Štěpán Veselý, Mirko Dohnal
}

\section{Introduction}

The task of the present paper is to outline a formalized qualitative model (FQM) of online trust (OT). OT is vital for establishing and maintaining commercial relationships on the internet (Grabner-Kraeuter, 2002; Van Der Heijden et al., 2003; Kim et al., 2008; 2012; Beldad et al., 2010; Delina \& Dráb, 2010). Trust is especially important when there is relative lack of certainty, formal rules, customs and agreements (Bradach et al., 1989; Gefen \& Straub, 2004), as is often the case with e-commerce interaction and online interaction in general (Gefen, 2000; McKnight et al., 2002; Gefen \& Straub, 2004).

OT is a multidimensional problem (McKnight \& Chervany, 2001; McKnight et al., 2002; Shankar et al., 2002; Chau et al., 2007; Beldad et al., 2010). FQMs are well suited for tackling multidimensional tasks. Also, FQMs are useful whenever vague and/or qualitative information need to be included into a model. In the OT context it might be necessary to consider for instance the influence of perceived social presence embedded in a web site (Gefen \& Straub, 2004; Cyr et al., 2007; Hassanein \& Head, 2007) or positive word of mouth (GrabnerKraeuter, 2002; Corbitt et al., 2003; Utz et al., 2012). It might be difficult or prohibitively costly to measure these influences precisely or quickly enough (e.g. when online companies need to meet deadlines for strategic decisions). It is appropriate to use an FQM then.

FQMs capture relationships among variables in the form of degraded (simplified) equations and statistical relations and/or in the form of common-sense heuristics (e.g. if $X$ goes up, $Y$ goes down with increasing rapidity). Qualitative methodology (Kuipers, 1989; Dohnal, 1991; Trave-Massuyes et al., 2004) has been used in some form to model for example investment decisions and economic problems (Benaroch \& Dhar, 1995; Hinkkanen et al., 2003; Curic et al., 2008; Konečný et al., 2010; Kocmanová et al., 2011) and a variety of engineering problems. See Bourseau et al. (1995), De Jong (2004) and Price et al. (2006) for an overview.

Qualitative models capture the fundamental features of a system under study, while eliminating quantitative detail (Kuipers, 1989). Qualitative modeling can be seen as one of the "uncertainty calculi", such as fuzzy sets (Zadeh, 1965; Dubois \& Prade, 1991; Hub \& Zatloukal, 2009), rough sets (Pawlak, 1982) and order of magnitude reasoning (Raiman, 1991). Such calculi can be helpful when dealing with online trust (Song et al., 2005; Chakraborty \& Chakraborty, 2007; Li et al., 2009; Li et al., 2012), especially under information shortage, measurement difficulties, time pressure to make decisions and/or uncertainty, or when several novel, subjective and/or difficult to measure (e.g. qualitative only) variables are being considered.

We propose a general methodological framework that enables incorporation of many even very vague and very diverse influences on OT in the context of e-commerce.

Although the specific version of the qualitative algorithm originally proposed by the second author has been used several times in the past, most recently in Vícha \& Dohnal (2008a, 2008b), Konečný et al. (2010), Kocmanová et al. (2011), Režňáková et al. (2012), this is actually the first paper where one of the principal aspects of the algorithm, namely selection of a consistent set of scenarios, is treated explicitly and in detail (see section 1.2).

\section{Method}

\subsection{Qualitative Models}

There are only three qualitative values: positive, zero and negative. The symbols used 
are $+, 0,-$, respectively. A qualitative scenario of a qualitative model is specified if all its $n$ qualitative variables $X \equiv\left(X_{1}, X_{2}, \ldots, X_{n}\right)$ are described by the qualitative triplets $(X, D X$, DDX), where DX and DDX are the first and second qualitative derivatives with respect to time (or an independent variable in general).

Let us suppose that the triplet $(++0) \equiv(T$, $D T$, DDT) represents risk aversion $R(t)$ as a function of time: it means that risk aversion is positive $(R=+)$, it is increasing in this example $(\mathrm{DR}=+)$ and the increase is linear $(\mathrm{DDR}=0)$ as the second derivative is zero.

Informally speaking, the first qualitative derivative tells us whether a variable is increasing, decreasing, or stable as a function of another variable - the first qualitative derivative is positive, negative, and zero in these cases, respectively. Again informally speaking, the second qualitative derivative tells us whether such a change (i.e. increase or decrease) in a variable is accelerating, stable or decelerating - the second qualitative derivative is positive, zero, and negative in these cases, respectively.

Looking at Fig. 1 on the next page, in pictures 21, 22 and 23 are instances of functions with positive first qualitative derivative, while in pictures 24, 25 and 26 we can see instances of functions with negative first qualitative derivative. A function with the first qualitative derivative equal to zero would be represented by a horizontal straight line (parallel with the $X$ axis).

Pictures 22 and 25 in Fig. 1 give examples of functions with the second qualitative derivative equal to zero. Pictures 21 and 26 represent functions with positive second qualitative derivative (the increase or decrease in $\mathrm{Y}$ is becoming more and more pronounced as a function of $X$ ), while pictures 23 and 24 represent functions with negative second qualitative derivative (we can see that the increase or decrease in $Y$ with respect to the increase in $\mathrm{X}$ gradually flattens out).

A typical example of a qualitative knowledge item can be formalized by a certain simple relation between two variables $\mathrm{X}$ and $\mathrm{Y}$. For example:

\section{If the price $X$ of a product is decreasing then the demand $Y$ is increasing.}

A formal interpretation of the qualitative knowledge item (1) is DY/DX = -, where DY/DX is the first qualitative derivative of $Y$ with respect to $X$ (in this example the derivative is negative).

Typical examples of qualitative relations are given in Fig. 1.

The identification numbers given in Fig. 1 are shape codes for the respective qualitative shapes, i.e. for instance 21 is a code number for function characterized by positive value of $Y$ and positive first and second qualitative derivatives of $Y$ with respect to $X$ (triplet +++ ). The identification numbers are employed in section 2.1 .

If the second derivative is not known then there are two variants of qualitative proportionality:

$M_{-}+$If $X$ is increasing then $Y$ is increasing.
If $X$ is decreasing then $Y$ is decreasing.
$M_{-}$If $X$ is increasing then $Y$ is decreasing.
If $X$ is decreasing then $Y$ is increasing.

For more details see e.g. Kuipers (1989), Parsons and Dohnal (1995), Trave-Massuyes et al. (2004).

A key concept in the approach to qualitative modeling presented here is "qualitative scenario" or simply "scenario".

In plain words, a scenario represents a concise qualitative description e.g. of an object or a system. An example of a scenario could be: If price of product $X$ increases, we will sell less $X$. Another example could be: If price of $X$ is stable and if X's reputation for quality increases, we will sell more $X$. These two examples describe a business development using two (price and sales) and three (price, sales and reputation for quality) variables, respectively.

Technically, a scenario consists of a series of variables. Each variable in the scenario is qualitatively described by its state (positive quantity, negative quantity, zero quantity) and by the first and second qualitative derivatives (usually with respect to time). As we already stated at the beginning of this section, these three qualities each variable can take can have only three possible values (+, - and 0$)$. The three qualities each variable can take can therefore be described by a sequence of three signs, i.e. a triplet, as was also already mentioned above.

To illustrate how a scenario is described using triplets, let us return to the example of a qualitative scenario mentioned previously: "If price of $X$ is stable and if $X$ 's reputation 


\section{Fig. 1: Examples of pair-wise qualitative equationless relations}
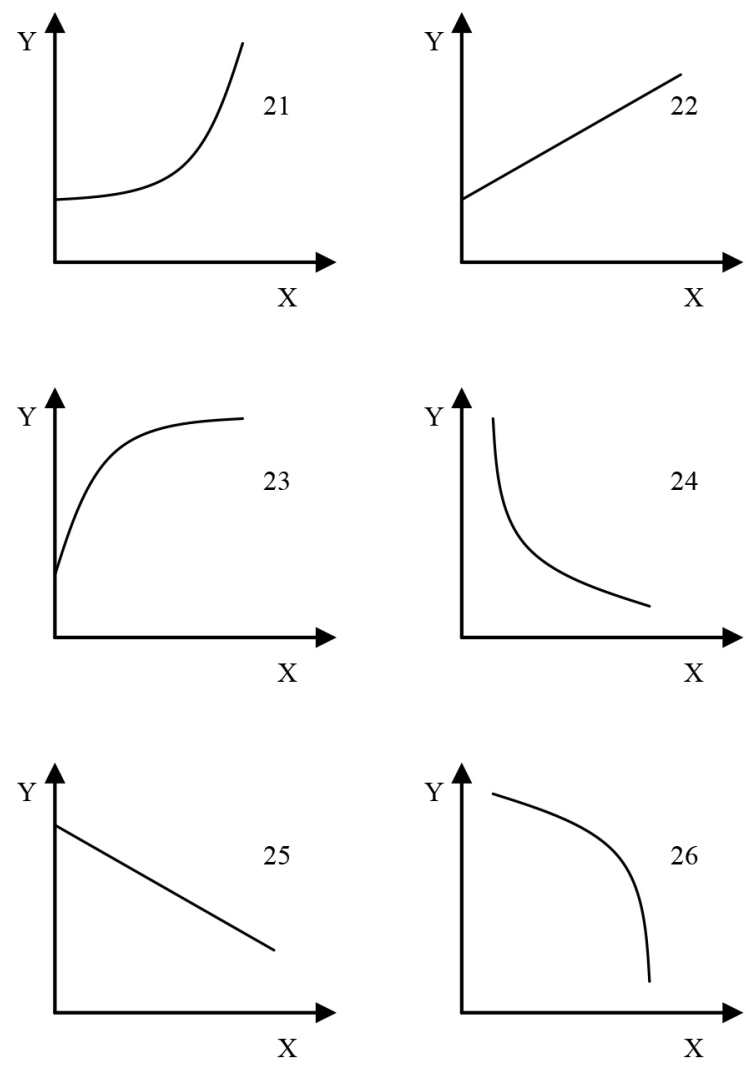

Source: own

for quality increases [let us assume that it increases linearly, so the second qualitative derivative is zero], we will sell more $X$ [let us assume that the increase in sales is slowing down because of gradual demand saturation, so the second qualitative derivative is negative]." This scenario can be described by the following series of triplets: +00 (price), ++0 (reputation), ++- (sales). Each scenario can be conveniently displayed in one row of a table where each cell contains qualitative description of one variable/ one triplet (see Tab. 2 in section 2.3).

As we will show next, some scenarios represent possible solutions of a qualitative model because they are consistent with a set of constraints based on available knowledge about a problem (e.g. about online trust and its determinants), while other scenarios are discarded because they are not consistent with the set of constraints (see section 1.2). Those discarded scenarios typically include certain relations between variables that are deemed unlikely or impossible based on the available knowledge (for example a negative relation between the level of trust towards an online site and this site's perceived quality and ease of use).

\subsection{Qualitative Vector Optimization}

Let us suppose that there are two independent variables $X_{1}, X_{2}$ and two objective functions $Q_{1}$, $Q_{2}$. There is a vector $F$ of constraints represented 
by a set of equationless relations among (some or all) of the variables $X_{1}, X_{2}, Q_{1}, Q_{2}$ :

$$
F\left(X_{1}, X_{2}, Q_{1}, Q_{2}\right)=0
$$

Such a set of constraints (4) constitutes the qualitative model of the problem at hand. A given model can have any number of independent variables and objective functions. A concrete example of a qualitative model (i.e. a set of constraints) describing the problem of online trust is given in (6) in section 2.2. Another very simple example of a constraint is given in (5) in this section. The constraint (5) consists of a single relation (namely the negative qualitative proportionality) between two variables, $\mathrm{X}$ and $\mathrm{Y}$.

This very simple model (5) will be used to illustrate how the constraints are employed to differentiate solutions of a problem that are consistent and solutions that are inconsistent with a model of a problem. In simple words we can say that solutions consistent with the model can happen, while inconsistent solutions can not take place in reality (as far as the knowledge used to construct the model is valid, of course). A given model (i.e. the set of constraints) can be based on empirical observation, on previously published results or on expert opinions.

The present qualitative algorithm is based on systematic confrontation of all possible triplets for each variable and the model itself. Scenarios (solutions) consistent with the model (i.e. with the set of constraints) are selected, while inconsistent scenarios are rejected. This type of solution is called brutal force in artificial intelligence.

We have now described, in general terms, how a qualitative model is solved. To recapitulate: the possible solutions (i.e. scenarios) are selected if they are consistent with a set of constraints formed by a set of qualitative relations between variables (such as (5) and (6) below). In the following paragraphs, we describe the process of solving a qualitative model in more detail. Readers interested mainly in the application of qualitative modeling to online trust can now skip directly to section 2 .

As we already understand on the conceptual level, scenarios selection can be seen as a consistency problem. At the beginning of the process of model development we usually have just a set of variables. Even at this initial stage it is possible to calculate solutions for the qualitative model. But it would not have any practical value, because we would obtain all "imaginable" scenarios, i.e. all combinations of qualitative values for each triplet.

Recall that in a scenario each variable is represented by a qualitative triplet (X, DX, DDX) - see section 1.1. In the present model of online trust we have 13 variables (see section 2.1), hence 13 triplets in each scenario. Each value (X, DX and DDX) in the triplet can be either,+- , or 0 . So, at this initial stage, there are $3^{3}=27$ possible combinations for each triplet. Since we have 13 such triplets (one for each variable) in each scenario, there are $27^{13}$ possible combinations of + , -, and 0 , where each combination represents one "imaginable" scenario.

This vast number of $27^{13}$ scenarios needs to be reduced to obtain a practical solution. This is done by including new knowledge in the model.

Before we show how the number of scenarios is reduced for the online trust model (see Tab. 3 in section 2.3), we will outline the basic principle of how inconsistent scenarios are discarded from the model with the inclusion of knowledge items.

Consider the following simple example. The interrelation

$$
\text { M_ } \quad X \quad Y
$$

states there is a negative relationship between variables $X$ and $Y$. All scenarios that violate this relationship must be discarded from the model when this knowledge item is entered. If we had a model with just two variables ( $\mathrm{X}$ and $\mathrm{Y}$ ), the model solution before and after entering interrelation (5) would look as shown in Tab. 1.

The solution in Tab. 1 is intuitively comprehensible: we must simply exclude all scenarios that have other values of first derivatives (DX) than either "+" for X and "-" for $Y$ or "-" for $X$ and "+" for $Y$. To see this, let us say that $X$ is increasing as a function of some variable $Z$ (e.g. time). This means that the first qualitative derivative of $X$ with respect to $Z$ is positive. If during the same change in $Z$ (e.g. time) $Y$ also increased, i.e. $D Y=+$ (with respect to $Z$ ), this would mean that $X$ and $Y$ moved in the same direction (both increased as a function of $Z$ ). This is represented by scenario 1 in Tab. 1. However, such a development is not possible given constraint (5) which requires a negative proportionality between $\mathrm{X}$ and $\mathrm{Y}$, i.e. when $X$ goes up, $Y$ must go down and vice 


\section{Tab. 1: Scenarios before and after entering an interrelation}

\begin{tabular}{|c|c|c|c|c|c|}
\hline \multicolumn{3}{|c|}{ Model before entering interrelation (5) } & \multicolumn{3}{|c|}{ Model after entering interrelation (5) } \\
\hline \multirow[b]{2}{*}{ Scenario } & \multicolumn{2}{|c|}{ Variables } & \multirow[b]{2}{*}{ Scenario } & \multicolumn{2}{|c|}{ Variables } \\
\hline & $\mathbf{x}$ & $\mathbf{Y}$ & & $\mathbf{x}$ & $\mathbf{Y}$ \\
\hline 1 & $++^{*}$ & $++^{*}$ & & & \\
\hline 2 & $+-^{*}$ & $+-^{*}$ & & & \\
\hline 3 & $+0^{*}$ & $+0^{*}$ & & & \\
\hline 4 & $++^{*}$ & $+0^{*}$ & & & \\
\hline 5 & $+-^{*}$ & $++^{*}$ & 5 & $+-^{*}$ & $++^{*}$ \\
\hline 6 & $+0^{*}$ & $+-^{*}$ & & & \\
\hline 7 & $++^{*}$ & $+-^{*}$ & 7 & $++^{*}$ & $+-^{*}$ \\
\hline 8 & $+-^{*}$ & $+0^{*}$ & & & \\
\hline 9 & $+0^{*}$ & $++^{*}$ & & & \\
\hline
\end{tabular}

Note: All variables are assumed to be positive. For simplicity, second derivatives are not considered in this example, thus the second derivative (DDX) is denoted by * in all triplets $\left({ }^{*}\right.$ can mean either,+- or 0$)$.

Source: own

versa. Consequently, only scenarios 5 and 7 in Tab. 1 are consistent with constraint (5).

In contrast, scenarios 1 and 2 (in Tab. 1) would be consistent with a constraint stipulating a positive proportionality between the variables. Scenarios 4, 6, 8 and 9 indicate there is no relation between the variables (when one variable changes in either direction, there is no change in the remaining variable). Scenario 3 describes a situation where there are no changes in either variable, thus it cannot be shown that there actually is a positive relation between $X$ and $Y$ as required by (5). Scenario 3 is therefore also discarded from the set of solutions consistent with constraint (5).

\section{Results and Discussion}

\subsection{Model Variables}

OT can be characterized by the following set of 13 variables, 11 independent variables and two objective functions:

\section{Objective functions:}

TRU Level of trust towards an online site/ company

RIS Perceived risk of interaction with the site/company (Hoffman et al., 1999; Yoon, 2002; Lacohee et al., 2006; Kim et al., 2008)
Independent variables:

FAM Familiarity with the site/company (Gefen, 2000; Gefen \& Straub, 2004)

MAR Level of the online company's market orientation, e.g. services customization (Srinivasan et al., 2002; Corbitt et al., 2003; Koehn, 2003)

SIT Perceived website quality and ease of use (McKnight \& Chervany, 2001; Grabner-Kraeuter, 2002; Liao et al., 2006; Chau et al., 2007; Kim et al., 2008, 2012)

SOC Social presence embedded in the web site (Gefen \& Straub, 2004; Cyr et al., 2007; Hassanein \& Head, 2007)

BEN Perceived benevolence of the online company (McKnight et al., 2002; Gefen \& Straub, 2004)

REP Site's/company's positive reputation (McKnight \& Chervany, 2001; Casalo et al., 2008; Kim et al., 2008)

WOM Level of positive of word of mouth (Grabner-Kraeuter, 2002; Corbitt et al., 2003; Lacohee et al., 2006)

PAR Site's/company's partnership with well known partners (Corbitt et al., 2003; Zhang, 2004; Kim et al., 2008; Hong \& Cho, 2011)

EXP User's web experience (McKnight et al., 2002; Corbitt et al., 2003; Lacohee et al., 2006; Metzger, 2006; Li et al., 2009) 
PRE Number of the user's previous positive experiences with online interaction (Gefen \& Straub, 2004; Flavian et al., 2006; Casalo et al., 2008)

TEC Perceived technological trustworthiness of the site/company (GrabnerKraeuter, 2002; Corbitt et al., 2003; Lacohee et al., 2006)

\subsection{Model Instructions}

The following set (6) of pair-wise qualitative relations is used to formalize relations among the set of variables from section 2.1. The set of interrelations is inspired by many dialogues with a team of experts and a group of internet users and by studies quoted above in section 2.1. The experts were MBA students at Brno University of Technology with substantial experience in online trade and/or marketing. The internet users were selected pre-graduate students at Brno University of Technology. The qualitative model is represented by the following set of relations (see Fig. 1):

\begin{tabular}{|c|c|c|c|}
\hline No. & Shape & $X$ & $Y$ (see Fig. 1) \\
\hline 1 & 23 & WOM & $F A M$ \\
\hline 2 & $M_{-}+(\operatorname{see}(2))$ & $S I T$ & $M A R$ \\
\hline 3 & $M_{-}+$ & $R E P$ & $M A R$ \\
\hline 4 & 21 & $W O M$ & $M A R$ \\
\hline 5 & 21 & $W O M$ & $S I T$ \\
\hline 6 & 21 & $T E C$ & $S I T$ \\
\hline 7 & 21 & $B E N$ & $S O C$ \\
\hline 8 & $M_{-}+$ & $R E P$ & $B E N$ \\
\hline 9 & $M_{-}+$ & WOM & $B E N$ \\
\hline 10 & 23 & $P A R$ & $B E N$ \\
\hline 11 & 23 & $P R E$ & $B E N$ \\
\hline 12 & $M_{-}+$ & $T E C$ & $B E N$ \\
\hline 13 & 23 & $W O M$ & $R E P$ \\
\hline 14 & $M_{-}+$ & $T E C$ & $R E P$ \\
\hline 15 & $M_{-}+$ & $T E C$ & $E X P$ \\
\hline 16 & 26 & RIS & $T R U$ \\
\hline 17 & 23 & FAM & $T R U$ \\
\hline 18 & 23 & $M A R$ & $T R U$ \\
\hline 19 & 23 & SIT & $T R U$ \\
\hline 20 & 23 & $S O C$ & $T R U$ \\
\hline 21 & 23 & $B E N$ & $T R U$ \\
\hline 22 & 23 & $R E P$ & $T R U$ \\
\hline 23 & 23 & $P A R$ & $T R U$ \\
\hline 24 & $M_{-}+$ & PRE & $T R U$ \\
\hline 25 & 24 & $F A M$ & $R I S$ \\
\hline 26 & 24 & $S I T$ & $R I S$ \\
\hline
\end{tabular}

$\begin{array}{llll}27 & M_{-} & B E N & R I S \\ 28 & 24 & R E P & R I S \\ 29 & 24 & P A R & R I S \\ 30 & 24 & \text { EXP } & R I S \\ 31 & M_{-}- & P R E & R I S \\ 32 & 24 & \text { TEC } & R I S\end{array}$

\subsection{Model Results - Scenarios}

The set of 23 scenarios - see Tab. 2 - is generated using software employed in Vícha and Dohnal (2008a; 2008b). The software was programmed by a group around the second author. As far as we know, there are currently no widespread commercial softwares for analyzing qualitative problems and different research groups often use their own softwares. However, analytical tools for qualitative computations can be programmed for example in MATLAB.

Different qualitative problems related to online trust can be easily solved using the set of scenarios in Tab. 2 which represent a complete description of all possible behaviors within the modeled system (constrained by relations given in (6)).

All variables in Tab. 2 are positive because of their very nature. Therefore the first values in all triplets (in Tab. 2) are always equal to + . For example scenario 12 is a steady state situation: all first and second derivatives are zeros. Therefore nothing is happening, there are no changes in time.

Scenarios 1-10 indicate e.g. that level of trust towards the company (TRU) increases as a function of time and perceived risk of interaction with the site/company (RIS) decreases as a function of time, while the rest of the variables go up. Scenarios 14-23 give the opposite. That means all independent variables in the present model are positively linked to TRU and negatively linked to RIS (this is not surprising, e.g. in Kim and Park (2013) six out of seven independent variables were positively related to online trust). There are, however, some differences in the precise character of the increase/decline of the variables with respect to the second derivatives. For example in scenario 1 all variables increase (or in the case of RIS decrease) more and more quickly (all triplets are equal to +++ and +--, respectively), whereas in scenario 10 all variables increase (or in the case of RIS decrease) with a decreasing rapidity (all triplets are equal to ++- and +-+, respectively). 


\section{Tab. 2: Online trust scenarios}

\begin{tabular}{|c|c|c|c|c|c|c|c|c|c|c|c|c|c|}
\hline \multirow{2}{*}{ Scenario } & \multicolumn{13}{|c|}{ Variables (see section 2.1) } \\
\hline & TRU & RIS & FAM & MAR & SIT & SOC & BEN & REP & WOM & PAR & EXP & PRE & TEC \\
\hline 1 & +++ & +-- & +++ & +++ & +++ & +++ & +++ & +++ & +++ & +++ & +++ & +++ & +++ \\
\hline 2 & ++ & +-+ & ++- & ++ & ++ & +++ & ++ & ++ & ++ & +++ & ++- & ++ & ++ \\
\hline 3 & ++ & +-+ & ++- & ++ & ++ & +++ & ++ & ++ & ++ & ++0 & ++- & ++- & ++ \\
\hline 4 & ++- & +-+ & ++- & ++- & ++ & +++ & ++ & ++- & ++ & ++- & ++- & ++- & ++ \\
\hline 5 & ++- & +-+ & ++- & ++ & ++ & ++0 & ++ & ++ & ++ & +++ & ++- & ++ & ++ \\
\hline 6 & ++- & +-+ & ++- & ++- & ++ & ++0 & ++ & ++ & ++ & ++0 & ++- & ++- & ++- \\
\hline 7 & ++- & +-+ & ++- & ++ & ++ & ++0 & ++ & ++ & ++ & ++- & ++- & ++- & ++ \\
\hline 8 & ++- & +-+ & ++- & ++ & ++ & ++- & ++ & ++ & ++ & +++ & ++- & ++ & ++ \\
\hline 9 & ++- & +-+ & ++- & ++ & ++ & ++ & ++ & ++ & ++ & ++0 & ++- & ++ & ++ \\
\hline 10 & ++ & +-+ & ++- & ++ & ++ & ++ & ++ & ++ & ++ & ++ & ++- & ++ & ++ \\
\hline 11 & $+0+$ & +0 & $+0+$ & $+0+$ & $+0+$ & $+0+$ & $+0+$ & $+0+$ & $+0+$ & $+0+$ & $+0+$ & $+0+$ & $+0+$ \\
\hline 12 & +00 & +00 & +00 & +00 & +00 & +00 & +00 & +00 & +00 & +00 & +00 & +00 & +00 \\
\hline 13 & +0 & $+0+$ & +0 & +0 & +0 & +0 & +0 & +0 & +0 & +0 & +0 & +0 & +0 \\
\hline 14 & +-+ & ++ & +-+ & +-+ & +-+ & +-+ & +-+ & +-+ & +-+ & +-+ & +-+ & +-+ & +-+ \\
\hline 15 & +-- & +++ & +-- & +-- & +- & +-+ & +-- & +-- & +- & +-+ & +- & +-- & +- \\
\hline 16 & +-- & +++ & +- & +- & +- & +-+ & +-- & +-- & +- & +-0 & +- & +-- & +- \\
\hline 17 & +-- & +++ & +-- & +- & +-- & +-+ & +- & +-- & +-- & +-- & +- & +-- & +- \\
\hline 18 & +-- & +++ & +-- & +-- & +- & +-0 & +-- & +-- & +-- & +-+ & +- & +-- & +- \\
\hline 19 & +- & +++ & +-- & +- & +- & +-0 & +- & +-- & +- & +-0 & +- & +- & +- \\
\hline 20 & +-- & +++ & +-- & +- & +- & +-0 & +- & +-- & +- & +-- & +- & +-- & +- \\
\hline 21 & +-- & +++ & +-- & +- & +- & +-- & +-- & +-- & +-- & +-+ & +- & +-- & +- \\
\hline 22 & +- & +++ & +-- & +- & +-- & +-- & +-- & +-- & +- & +-0 & +- & +-- & +- \\
\hline 23 & +- & +++ & +- & +- & +- & +- & +- & +-- & +- & +- & +- & +- & +- \\
\hline
\end{tabular}

Source: Authors

The nature of one of the objective functions (TRU) requires maximization, whereas the other objective function (RIS) requires minimization, hence, there are 10 relatively favorable scenarios, i.e. scenarios $1-10$, and 10 relatively undesirable ones, scenarios 14-23.

Let us for example suppose that an online company is uncertain about the effect an increase in the variable "social presence embedded in the web site" (SOC) will have on "perceived risk of interaction with the site/company" (RIS). Having a look at scenarios 1-10 (and columns RIS and SOC) in Tab. 2 would tell the company managers that the effect ought to be positive. Also, it seems that the effect would be almost always the same (with the exception of scenario 1) irrespective of the speed with which the changes in SOC are implemented.

We need to keep in mind, though, that FQMs are information non-intensive. This implies that they usually capture only the most robust aspects of the described systems. This is the case especially when the solutions are narrowed down to just a few scenarios (i.e. when the amount of available qualitative knowledge is large, see Tab. 3 and text below). More information intensive methods (e.g. fuzzy mathematical methods or statistics) can be subsequently used to gain additional insights into the studied systems/ problems. However, this is not always an option in high-speed environments, for example because collection of quantitative data takes time. 
We can say that the present model is well specified by interrelations given in (6), which causes it to be quite restrictive, i.e. there is little variability in the scenarios obtained. If less input knowledge (such as (6)) was available, the model would be less well specified and consequently less restrictive, and more variability would be encountered in the scenarios obtained (e.g. certain variables would be linked to certain other variables positively in a given subset of scenarios and negatively in another subset).

Relying on a restrictive model has a potential disadvantage in that certain subtle relations or differences may be disregarded in the model in order to obtain the set of the most robust or most typical scenarios (e.g. in the present model we ignore the possibility that the relation between SIT and TRU might be partially culture-sensitive, see Park et al., 2012). On the other hand, it is also possible to develop an ad hoc qualitative model "typical" for an unusual situation/system.

Table 3 displays the number of online trust scenarios obtained using the basic principle of consistency outlined in section 1.2. The columns "Interrelations entered" give the range of interrelations entered (i.e. 1-3 means that interrelations 1, 2 and 3 from (6) have been entered into the model).

Using the principle of consistency, the vast number of "imaginable" scenarios $\left(27^{13}\right)$ has been rapidly reduced by entering available pieces of knowledge.

As is apparent from Tab. 3 the solutions of qualitative models become interpretable after including about 25 pair-wise interrelations between variables. This statement is true for models with about the same number of variables we have in our model of online trust. More (less) knowledge items need to be entered if the model features more (less) variables.

It can also be observed that entering certain interrelations (e.g. interrelations number 5,13 , 14, 18, 26 - see Tab. 3) does not reduce the number of scenarios obtained. The reason is that the respective set of scenarios before the particular interrelation was entered had already been consistent with that interrelation.

FQM development is a multi-step process, and the present model can be modified/ upgraded to address specific practical and

\section{Tab. 3: Number of scenarios dependent on the pair-wise relations entered in the model}

\begin{tabular}{l|r|r|c} 
Interrelations entered & Number of scenarios & Interrelations entered & Number of scenarios \\
\hline None & $27^{13}$ & $1-16$ & 819 \\
\hline All variables positive & $9^{13}$ & $1-17$ & 187 \\
\hline 1 & 407953774917 & $1-18$ & 187 \\
\hline $1-2$ & 45328197213 & $1-19$ & 187 \\
\hline $1-3$ & 5036466357 & $1-20$ & 187 \\
\hline $1-4$ & 731794257 & $1-21$ & 187 \\
\hline $1-5$ & 731794257 & $1-22$ & 187 \\
\hline $1-6$ & 176969853 & $1-23$ & 187 \\
\hline $1-7$ & 28402569 & $1-24$ & 59 \\
\hline $1-8$ & 2421009 & $1-25$ & 23 \\
\hline $1-9$ & 1594323 & $1-26$ & 23 \\
\hline $1-10$ & 255879 & $1-27$ & 23 \\
\hline $1-11$ & 54675 & $1-28$ & 23 \\
\hline $1-12$ & 45927 & $1-29$ & 23 \\
\hline $1-13$ & 45927 & $1-30$ & 23 \\
\hline $1-14$ & 45927 & $1-31$ & 23 \\
\hline $1-15$ & 5103 & $1-32$ & 23 \\
\hline
\end{tabular}

Note: * We assume that all variables are positive later on (in this table) as well. 
theoretical needs. Also, it is possible to calculate all possible transitions between the qualitative scenarios (Režňáková et al., 2012). The possibility to update qualitative models quickly and easily based on an inflow of new qualitative information can be an advantage in turbulent environments such as electronic retail markets or the computer and mobile phones industries.

The obvious limitation of FQM is that qualitative reasoning can answer qualitative queries only, not quantitative ones, and thus can serve just as a complement to the existing quantitative methods (and/or as a rigorous formalization of qualitative methods, such as case studies). However, inclusion of mathematical equations into qualitative models is possible (Vícha \& Dohnal, 2008a; 2008b).

FQMs can enrich the methodological instrumentarium used in the study of OT (e.g. Grabner-Krauter \& Kaluscha (2003) advocate the use of a broad spectrum of research tools). The main advantages of FQMs are:

- No numerical values of constants and parameters are needed (i.e. information non-intensive).

- The set of possible solutions (scenarios) is complete, i.e. there cannot be any other qualitative scenarios that are not generated by the qualitative model.

- FQMs are flexible, diverse variables can be included.

- They are inexpensive and readily understandable by practitioners.

\section{Conclusion}

Qualitative approach has much to offer when highly complex and/or partially vague problems such as OT are examined. In the present study of OT determinants a formal tool for dealing with data of non-numerical nature was employed to generate a FQM consisting of 23 possible scenarios. The model obtained is definitely not the only possible alternative. Many modifications, upgrades and extensions are possible. The paper presents just methodology and a simple model as a demonstration. Also, this is the first paper where one of the principal aspects of the present qualitative algorithm, namely selection of a consistent set of scenarios, is treated explicitly and in detail.

FQMs can complement established tools for OT analysis with very little additional cost. This might be profitable especially under information shortage, measurement difficulties, time pressure to make decisions and/or uncertainty, or when several novel, subjective and/or difficult to measure (e.g. qualitative only) variables are considered when dealing with online trust in the e-commerce context.

\section{References}

Beldad, A., De Jong, M., \& Steehouder, M. (2010). How shall I trust the faceless and the intangible? A literature review on the antecedents of online trust. Computers in Human Behavior, 26(5), 857-869. doi:10.1016/j. chb.2010.03.013.

Benaroch, M., \& Dhar, V. (1995). Controlling the complexity of investment decisions using qualitative reasoning techniques. Decision Support Systems, 15(2), 115-131. doi:10.1016/0167-9236(94)00031-M.

Bourseau, P., Bousson, K., Dague, P., Dormoy, J.L., Evrard, J.M., Guerrin, F., Leyval, L., Lhomme, O., Lucas, B., Missier, A., Montmain, J., Piera, N., Rakoto-Ravalontsalama, N., Steyer, J.P., Tomasena, M., TraveMassuyes, L., Vescovi, M., Xanthakis, S., \& Yannou, B. (1995). Qualitative reasoning: A survey of techniques and applications. Al Communications, 8(3-4), 119-192. doi:10.3233/ AIC-1995-83-401.

Bradach, J.L., \& Eccles, R.G. (1989). Price, authority, and trust: From ideal types to plural forms. Annual Review of Sociology, 15, 97-118. doi:10.1146/annurev.so.15.080189.000525.

Casalo, L., Flavian, C., \& Guinaliu, M. (2008). The role of perceived usability, reputation, satisfaction and consumer familiarity on the website loyalty formation process. Computers in Human Behavior, 24(2), 325-345. doi:10.1016/j.chb.2007.01.017.

Chakraborty, C., \& Chakraborty, D. (2007). Fuzzy rule base for consumer trustworthiness in Internet marketing: An interactive fuzzy rule classification approach. Intelligent Data Analysis, 11(4), 339-353. doi:10.1016/j. dss.2003.12.005.

Chau, P.Y.K., Hu, P.J.-H., Lee, B.L.P., \& Au, A.K.K. (2007). Examining customers' trust in online vendors and their dropout decisions: An empirical study. Electronic Commerce Research and Applications, 6(2), 171-182. doi:10.1016/j.elerap.2006.11.008.

Corbitt, B.J., Thanasankit, T., \& Yi, H. (2003). Trust and e-commerce: A study of consumer perceptions. Electronic Commerce Research 
and Applications, 2(3), 203-215. doi:10.1016/ S1567-4223(03)00024-3.

Curic, A., Kern, T., \& Rajkovic, V. (2008). A qualitative model for road investment appraisal. Transport Policy, 15(4), 225-231. doi:10.1016/j.tranpol.2008.05.003.

Cyr, D., Hassanein, K., Head, M., \& Ivanov, A. (2007). The role of social presence in establishing loyalty in e-Service environments. Interacting with Computers, 19(1), 43-56. doi:10.1016/j.intcom.2006.07.010.

De Jong, H. (2004). Qualitative simulation and related approaches for the analysis of dynamic systems. Knowledge Engineering Review, 19(2), 93-132. doi:10.1017/S0269888904000177.

Delina, R., \& Dráb, R. (2010). Socioekonomické aspekty budovania dôvery na elektronických obchodných platformách. E\&M Ekonomie a Management, 13(4), 110-122.

Dohnal, M. (1991). A methodology for common-sense model development. Computers in Industry, 16(2), 141-158. doi:10.1016/01663615(91)90086-O.

Dubois, D., \& Prade, H. (1991). Fuzzy sets in approximate reasoning, part 1: Inference with possibility distributions. Fuzzy Sets and Systems, 40(1), 143-202. doi:10.1016/01650114(91)90050-Z.

Flavian, C., Guinaliu, M., \& Gurrea, R. (2006). The role played by perceived usability, satisfaction and consumer trust on website loyalty. Information \& Management, 43(1), 1-14. doi:10.1016/j.im.2005.01.002.

Gefen, D. (2000). E-commerce: The role of familiarity and trust. Omega, 28(6), 725-737. doi:10.1016/S0305-0483(00)00021-9.

Gefen, D., \& Straub, D.W. (2004). Consumer trust in B2C e-commerce and the importance of social presence: Experiments in e-products and e-services. Omega, 32(6), 407424. doi:10.1016/j.omega.2004.01.006.

Grabner-Kraeuter, S. (2002). The role of consumers' trust in online-shopping. Journal of Business Ethics, 39(1-2), 43-50. doi:10.1023/A:1016323815802.

Grabner-Krauter, S., \& Kaluscha, E.A. (2003). Empirical research in on-line trust: A review and critical assessment. International Journal of Human-Computer Studies, 58(6), 783-812. doi:10.1016/S1071-5819(03)00043-0.

Hassanein, K., \& Head, M. (2007). Manipulating perceived social presence through the web interface and its impact on attitude towards online shopping. International
Journal of Human-Computer Studies, 65(8), 689-708. 10.1016/j.jjhcs.2006.11.018.

Hinkkanen, A., Lang, K.R., \& Whinston, A.B. (2003). A set-theoretical foundation of qualitative reasoning and its application to the modeling of economics and business management problems. Information Systems Frontiers, 5(4), 379-399. doi:10.1023/B:ISFI.0000005652.72048.4d.

Hoffman, D.L., Novak, T.P., \& Peralta, M. (1999). Building consumer trust online. Communications of the ACM, 42(4), 80-85. doi:10.1145/299157.299175.

Hong, I.B., \& Cho, H. (2011). The impact of consumer trust on attitudinal loyalty and purchase intentions in B2C e-marketplaces: Intermediary trust vs. seller trust. International Journal of Information Management, 31(5), 469-479. doi:10.1016/j.ijinfomgt.2011.02.001.

Hub, M., \& Zatloukal, M. (2009). Towards establishing a score of usability evaluation. E\&M Ekonomie a Management, 12(2), 156-159.

Jahn, J. (2004). Vector optimization: Theory, applications, and extensions. Berlin Heidelberg: Springer.

Kim, D.J., Ferrin, D.L., \& Rao, H.R. (2008). A trust-based consumer decision-making model in electronic commerce: The role of trust, perceived risk, and their antecedents. Decision Support Systems, 44(2), 544-564. doi:10.1016/j.dss.2007.07.001.

Kim, H.W., Xu, Y.J., \& Gupta, S. (2012). Which is more important in Internet shopping, perceived price or trust? Electronic Commerce Research and Applications, 11(3), 241-252. doi:10.1016/j.elerap.2011.06.003.

Kim, S., \& Park, H. (2013). Effects of various characteristics of social commerce (s-commerce) on consumers' trust and trust performance. International Journal of Information Management, 33(2), 318-332. doi:10.1016/j.jinfomgt.2012.11.006.

Kocmanová, A., Dohnal, M., \& Meluzín, T. (2011). Qualitative equationless models as simple integrators of vague sustainability knowledge items. Transformations in Business \& Economics, 11(3), 187-196.

Konečný, J., Vícha, T., \& Dohnal, M. (2010). Qualitative phase portrait of modified Black-Scholes model. Expert Systems with Applications, 37(5), 3823-3826. doi:10.1016/j. eswa.2009.11.037.

Koehn, D. (2003). Thenature of and conditions for online trust. Journal of Business Ethics, 43(1-2), 3-19. doi:10.1023/A:1022950813386. 
Kuipers, B. (1989). Qualitative reasoning: Modeling and simulation with incomplete knowledge. Automatica, 25(4), 571-585. doi:10.1016/0005-1098(89)90099-X.

Lacohee, H., Phippen, A.D., \& Furnell, S.M. (2006). Risk and restitution: Assessing how users establish online trust. Computers \& Security, 25(7), 486-493. doi:10.1016/j. cose.2006.09.001.

Li, W., Liu, J., Wang, H., Calzada, A., Rodriguez, R.M., \& Martinez, L. (2012). A qualitative decision making model based on belief linguistic rule based inference methodology. International Journal of Uncertainty Fuzziness and KnowledgeBased Systems, 20(SI), 105-118. doi:10.1142/ S0218488512400089.

Li, Y.-M., Kao, C.-P., \& Trepps: (2009). A trust-based recommender system for peer production services. Expert Systems with Applications, 36(2), 3263-3277. doi:10.1016/j. eswa.2008.01.078.

Liao, C., Palvia, P., \& Lin, H.-N. (2006). The roles of habit and web site quality in e-commerce. International Journal of Information Management, 26(6), 469-483. doi:10.1016/j.ijinfomgt.2006.09.001.

McKnight, D.H., \& Chervany, N.L. (2001). What trust means in e-commerce customer relationships: An interdisciplinary conceptual typology. International Journal of Electronic Commerce, 6(2), 35-59. doi:10.1080/1086441 5.2001.11044235.

McKnight, D.H., Choudhury, V., \& Kacmar, C. (2002). Developing and validating trust measures for e-commerce: An integrative typology. Information Systems Research, 13(3), 334-359. doi:10.1287/isre.13.3.334.81.

Metzger, M.J. (2006). Effects of site, vendor, and consumer characteristics on web site trust and disclosure. Communication Research, 33(3), 155-179. doi:10.1177/0093650206287076.

Park, J., Gunn, F., \& Han, S.-L. (2012). Multidimensional trust building in e-retailing: Cross-cultural differences in trust formation and implications for perceived risk. Journal of Retailing and Consumer Services, 19(3), 304-312.

Parsons, S., \& Dohnal, M. (1995). The qualitative and semiqualitative analysis of environmental problems. Environmental Software, 10(2), 75-85.

Pawlak, Z. (1982). Rough sets. Journal of Computer \& Information Sciences, 11(5), 341-356. doi:10.1007/BF01001956.
Price, C.J., Trave-Massuyes, L., Milne, R., Ironi, L., Forbus, K., Bredeweg, B., Lee, M.H., Struss, P., Snooke, N., Lucas, P., Cavazza, M., \& Coghill, G.M. (2006). Qualitative futures. Knowledge Engineering Review, 21(4), 317334. doi:10.1017/S026988890600097X.

Raiman, O. (1991). Order of magnitude reasoning. Artificial Intelligence, 51(1-3), 11-38. doi:10.1016/0004-3702(91)90107-U.

Režňáková, M., Wouters, H., Dohnal, M., \& Brož, Z. (2012). Equationless qualitative models of science parks: Part II, optimisation by time sequences of scenarios. International Journal of Technology Intelligence and Planning, 8(3), 295-306. doi:10.1504/IJTIP.2012.048575.

Shankar, V., Urban, G.L., \& Sultan, F. (2002). Online trust: A stakeholder perspective, concepts, implications, and future directions. Journal of Strategic Information Systems, 11(3-4), 325-344. doi:10.1016/S0963-8687(02)00022-7.

Song, S.S., Hwang, K., Zhou, R.F., \& Kwok, Y.K. (2005). Trusted P2P transactions with fuzzy reputation aggregation. IEEE Internet Computing, 9(6), 24-34. doi:10.1109/ MIC.2005.136.

Srinivasan, S.S., Anderson, R., \& Ponnavolu, K. (2002). Customer loyalty in e-commerce: An exploration of its antecedents and consequences. Journal of Retailing, 78(1), 41-50.

Trave-Massuyes, L., Ironi, L., \& Dague, P. (2004). Mathematical foundations of qualitative reasoning. Al Magazine, 24(4), 91-106. doi:10.1609/aimag.v24i4.1733.

Utz, S., Kerhof, P., \& Van Den Bos, J. (2012). Consumers rule: How consumer reviews influence perceived trustworthiness of online stores. Electronic Commerce Research and Applications, 11(1), 49-58. doi:10.1016/j. elerap.2011.07.010.

Van Der Heijden, H., Verhagen, T., \& Creemers, M. (2003). Understanding online purchase intentions: Contributions from technology and trust perspectives. European Journal of Information Systems, 12(1), 41-48. doi:10.1057/palgrave.ejis.3000445.

Vícha, T., \& Dohnal, M. (2008a). Qualitative feature extractions of chaotic systems. Chaos, Solitons \& Fractals, 38(2), 364-373. doi:10.1016/j.chaos.2008.01.008.

Vícha, T., \& Dohnal, M. (2008b). Qualitative identification of chaotic systems behaviours. Chaos, Solitons \& Fractals, 38(1), 70-78. doi:10.1016/j.chaos.2008.01.027. 
Yoon, S.J. (2002). The antecedents and consequences of trust in online-purchase decisions. Journal of Interactive Marketing, 16(2), 47-63. doi:10.1002/dir.10008.

Zadeh, L.A. (1965). Fuzzy Sets. Information and Control, 8(3), 338-353. doi:10.1016/S00199958(65)90241-X.

Zhang, H. (2004). Trust-promoting seals in electronic markets: Impact on online shopping decisions. Journal of Information Technology Theory \& Application, 6(4), 29-40. doi:10.1300/ J057v09n01_13.
Mgr. Štěpán Veselý

Brno University of Technology Faculty of Business and Management

Department of Economics stepan.vesely@seznam.cz.

prof. Ing. Mirko Dohnal, DrSc.

Brno University of Technology

Faculty of Business and Management

Department of Economics dohnal@fbm.vutbr.cz. 


\section{Abstract}

\section{FORMALIZED QUALITATIVE MODELING OF ONLINE TRUST: INTRODUCTION OF THE METHOD AND A DETAILED EXAMPLE}

\section{Štěpán Veselý, Mirko Dohnal}

The paper presents a simple qualitative model of online trust in the context of e-commerce. Qualitative models use just three values: Positive/Increasing, Zero/Constant and Negative/ Decreasing. Such quantifiers of trends are the least information intensive. Qualitative models can be useful, since models of online trust include such variables as e.g. Perceived website quality and ease of use (SIT) or Company's positive reputation (REP) that are sometimes difficult or costly to quantify. Hence, a significant fraction of available information about online trust is not of numerical nature, e.g. if SIT is decreasing then online trust is decreasing as well. Such equationless relations are studied in this paper. The model has 13 variables and 32 pair-wise interrelations among them. The set of variables and interrelations was established based on discussions with experts and internet users. The model is solved and 23 solutions, i.e. scenarios are obtained (thus, we reduce a vast set of all "imaginable" scenarios concerning online trust to a manageable list of scenarios). All qualitative states, and the first and second qualitative derivatives of all variables are specified for each scenario. Many modifications, upgrades and extensions of the present model are easy within the methodological framework introduced in the paper. Qualitative modeling can be seen as one of the uncertainty calculi, such as fuzzy sets and rough sets, that can be helpful e.g. under information shortage (for example when new website is about to be launched and/or when novel, subjective or difficult to measure variables are considered). The paper is self-contained and no a priori knowledge of qualitative modeling is required on the reader's part.

Key Words: Trust, online, e-commerce, internet, qualitative model, multidimensional, formalized, methodology.

JEL Classification: C65, D80, L81, M31.

DOI: 10.15240/tul/001/2016-2-014 